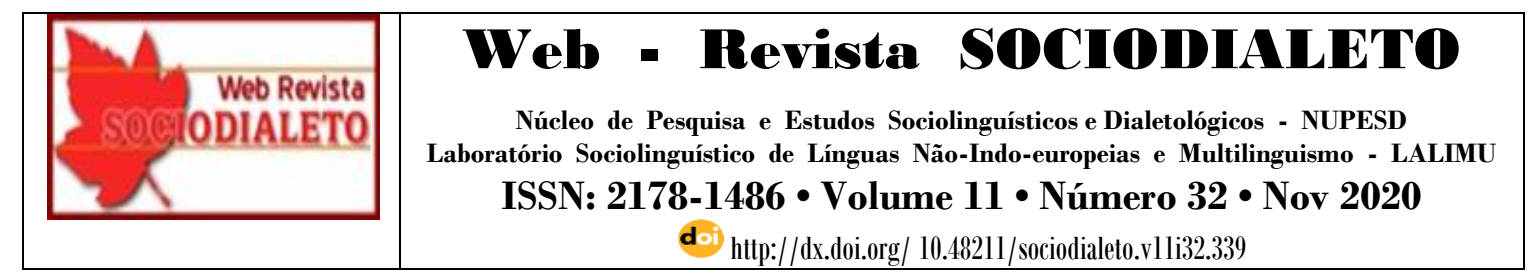

\title{
APONTAMENTOS DA LÍNGUA OFAIÉ (MACRO-JÊ) DIANTE DO CONTATO LINGUÍSTICO
}

\author{
Rogério Vicente Ferreira (UFMS) ${ }^{1}$ \\ rogerio.v.ferreira@ufms.br \\ Nataniel dos Santos Gomes (UEMS-CG) ${ }^{2}$ \\ natanielgomes@gmail.com
}

\begin{abstract}
RESUMO: Este artigo apresenta uma reflexão sobre as palavras neológicas na língua Ofaié, oriundas do contato linguístico. A língua Ofaié está em perigo de extinção, sendo classificada como pertencente ao Tronco Macro-Jê. Entre os fatores que colaboraram para que a língua chegasse a este estágio, temos a assimetria predominante em relação ao português, o que, certamente, contribuiu como um aspecto de maior impacto. O povo ofaié se encontra entre a minoria que possui sua língua nativa ameaçada. Diante disso, olhar para as criações lexicais como parte do contato com a língua majoritária, ou seja, a língua portuguesa, também é uma forma de preservar a memória lexical desse povo. Este trabalho segue bases epistemológicas de Couto (2009), Trasck (2004), Weinreich (1970), Correira (2012), Langacker (1972), entre outros. Esta reflexão é parte da pesquisa desenvolvida sobre o léxico da língua ofaié.
\end{abstract}

PALAVRAS-CHAVE: Língua Ofaié; Criação lexical; Línguas de contato

ABSTRACT: This article presents a reflection on the neologisms in the Ofaie language, derived from linguistic contact. The Ofaié language is in danger of extinction, being classified as belonging to the MacroJê trunk. Among the factors that contributed to this language reaching this stage is the predominant asymmetry in relation to Portuguese, which certainly contributed as an aspect of greater impact. The Ofaié people are among the minority groups that have their native languages threatened. Therefore, looking at lexical creations as part of contact with the majority language, that is Brazilian Portuguese, is also a way of preserving the lexical memory of these people. This work follows the epistemological foundations of Couto (2009), Trasck (2004), Weinreich (1970), Correira (2012), Langacker (1972), and others. This reflection is part of the research developed on the lexicon of the Ofaié language.

KEYWORDS: Ofaié language; Lexical creation; Contact languages

\section{Introdução}

Os pontos mais perceptíveis quando nos deparamos com a questão do contato linguístico por um determinado povo, são as criações lexicais. a partir delas é possível observar com quais línguas e em que grau a língua nativa sofreu influência. Couto (2009,

\footnotetext{
${ }^{1}$ Professor Associado III na Universidade Federal de Mato Grosso do Sul (UFMS).

${ }^{2}$ Professor da graduação e do programa de pós-graduação (Mestrado Acadêmico em Letras e Mestrado Profissional em Letras) da Universidade Estadual de Mato Grosso do Sul (UEMS-CG).
} 


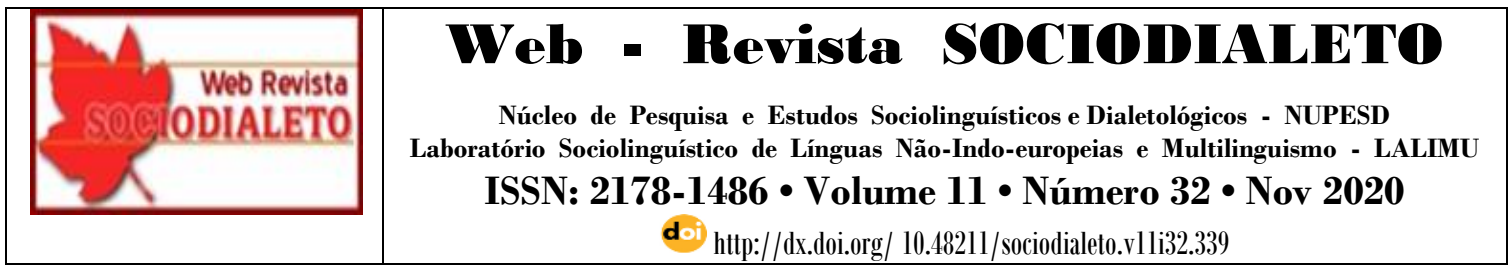

p. 50) coloca que "populações se deslocam (conceito espacial) para o território de outra população. A co-presença no espaço leva à interação entre os dois povos/línguas, que pode levar a um estado de comunhão que, por seu turno, poderá resultar em comunicação". Foi exatamente o que ocorreu com os povos indígenas. Uma consequência desse contato é a variedade de palavras novas.

No rol lexical dos Ofaié é possível encontrar palavras novas devido o contato com outros indígenas e não indígenas. Lyons (1979) afirma que:

[...] línguas em contato geográfico ou cultural 'tomam' muito livremente palavras uma das outras; pois as palavras tendem a viajar através de fronteiras geográficas e linguísticas com o objeto ou costume a que se referem [...] (LYONS, 1979, p. 25)

Os Ofaié não fogem a essa "regra", como se observará mais adiante (cf. quadro 1), este povo já vinha tendo contato linguístico com outros povos, tanto que absorveu algumas palavras, registrada tanto por Loukotka (1931), Nimuendaju (1932 [1909]). Entre as formas neológicas encontradas tanto na lista vocabular destes estudiosos, quanto as que foram coletadas, é fácil encontrar os itens lexicais por meio de empréstimos, como o caso para a palavra "pão", que é falada [фã̃̃], ortograficamente <phãu>.

\section{Povo e língua Ofaié}

Ofaié ${ }^{3}$ é autodenominação do povo indígena que vive em duas áreas nas subbacias do rio Verde e Pardo, incluindo o rio Taquaraçu e outros córregos em direção ao rio Parará. A outra área está na sub-bacia do rio Ivinhema, além da serra de Maracaju, pelas sub-bacias do rio Miranda e Negro, em Mato Grosso do Sul (DUTRA, 2011).

\footnotetext{
${ }^{3}$ Para Dutra (2017), os Ofaié têm sido registrados de diferentes maneiras, tais como, Opayé, Opaié, Ofaié, Faiá, Faié, Afaiá, Araés, Ypaié, Xavante, Chavante, Shavante, Chavante-Ofaié, Chavante-Opaié, Kurura, Guachi, Wahéi entre outros.
} 


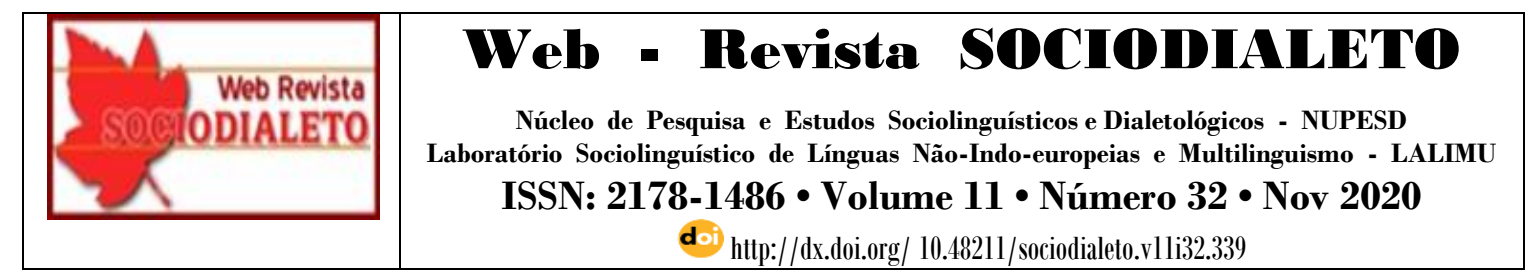

Os Ofaié vivem atualmente em uma área de 1.144 hectares, dividida em duas aldeias, localizadas na cidade de Brasilândia, Mato Grosso do Sul. Na área onde vivem há também não índios, e povos da etnia Guarani e Kaiowá. (DUTRA, 2011)

De acordo Silva (2012), até 2006, na aldeia ofayé havia 75 indivíduos, espalhados em 23 famílias: 46 ofayé, 11 kaiwá, 13 guarani-nhandeva e 5 não indígenas. Já para a Fundação Nacional da Saúde (FUNASA, 2010), são 105 indivíduos divididos em 46 famílias: 60 ofayé, 36 kaiwá, 5 guarani, 2 guarani-kaiwá e 2 não indígenas. Tudo isso serve para justificar uma interétnia que acabou resultando numa forte variação linguística.

Figura 1: Território Ofaié

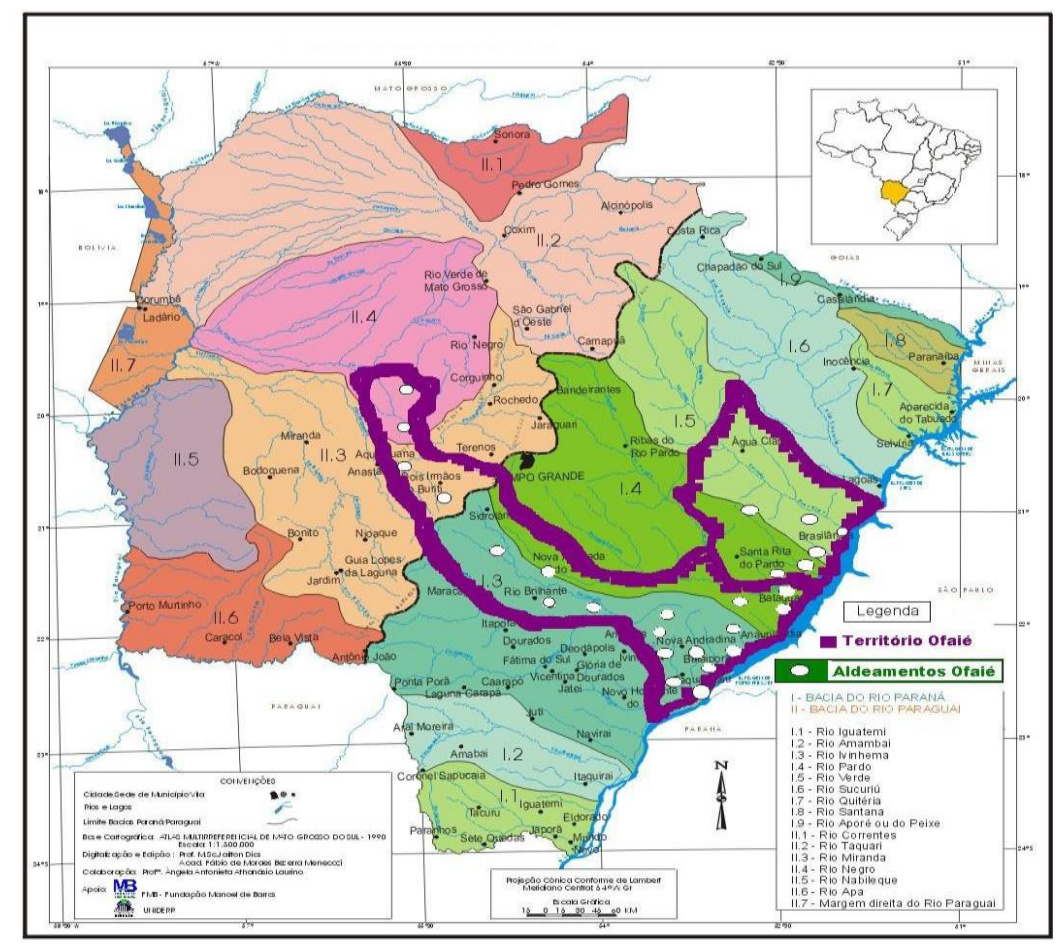

Fonte: Atlas MR-MS 1990, adaptado por Dutra, 2004 apud Silva (2012, p. 32)

Não muito diferente do histórico vivido por outros povos indígenas, os Ofaié foram vítimas de genocídio e longas perseguições, o que gerou a noção de que eles 


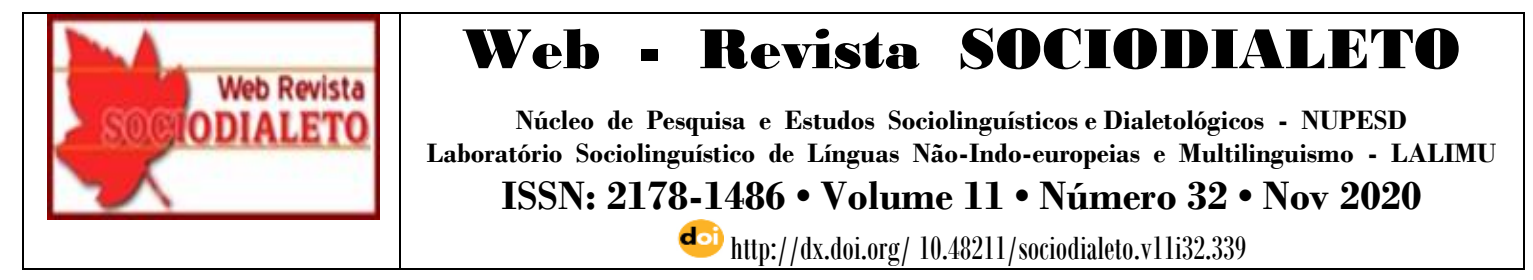

haviam sido exterminados. Porém, não foi o que ocorreu. Mesmo diante de condições precárias de vida, sofrimento, adversidades extremas, lutas por território, os Ofaié permaneceram unidos, sempre buscando uma perspectiva de vida melhor.

De acordo com Siqueira,

A situação de conflito na terra Ofaié sempre foi presente, só foi minimizada quando a Companhia Energética de São Paulo (CESP) comprou uma área destinada à criação da reserva indígena Ofaié de 484 hectares (1997) e os deslocou para lá. (SIQUEIRA, 2018, p. 2)

Segundo Rodrigues (1986), o Ofaié é considerada uma língua sem família linguística, mas que pertencem ao tronco Macro-Jê. Podemos destacar três estudos linguístico sobre os: (i) Ihering (1912), uma comparação linguística coligida por Nimuendajú sobre os Chavantes de Campos Novos (Oti) e os Chavantes Opaié; (ii) Nimuendajú (1932), uma lista vocabular de 330 palavras, por fim, (iii) Gudschinsky (1971 [1958]) sob patrocínio do Museu Nacional faz uma análise fonológica e morfológica junto ao grupo que vivia na época na Fazenda Primavera, tal estudo publicado em 1971 e posteriormente em 1974 - foi o que confirmou a classificação da língua Ofaié como parte do Tronco Macro-Jề ${ }^{4}$. As línguas desse tronco estão distribuídas no Rio Grande do Norte, Pará, Tocantins, Goiás, Mato Grosso, São Paulo, Santa Catarina, Paraná e Rio Grande do Sul.

\footnotetext{
${ }^{4} \mathrm{O}$ tronco Macro-Jê é composto por 9 famílias linguísticas, 21 línguas e seus dialetos. As línguas Krenák, Guató, Ofayé, Rikbaktsá e Yatê são únicas dentro das suas famílias.
} 


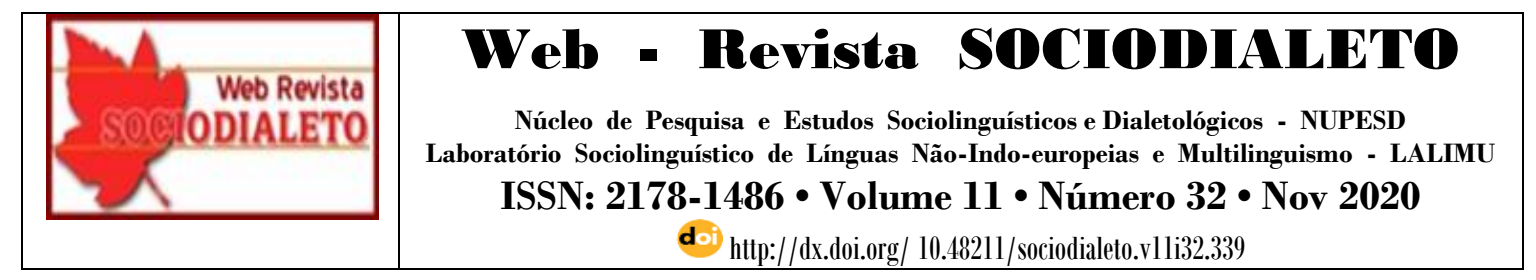

Figura 2: Etnias indígenas de Mato Grosso do Sul

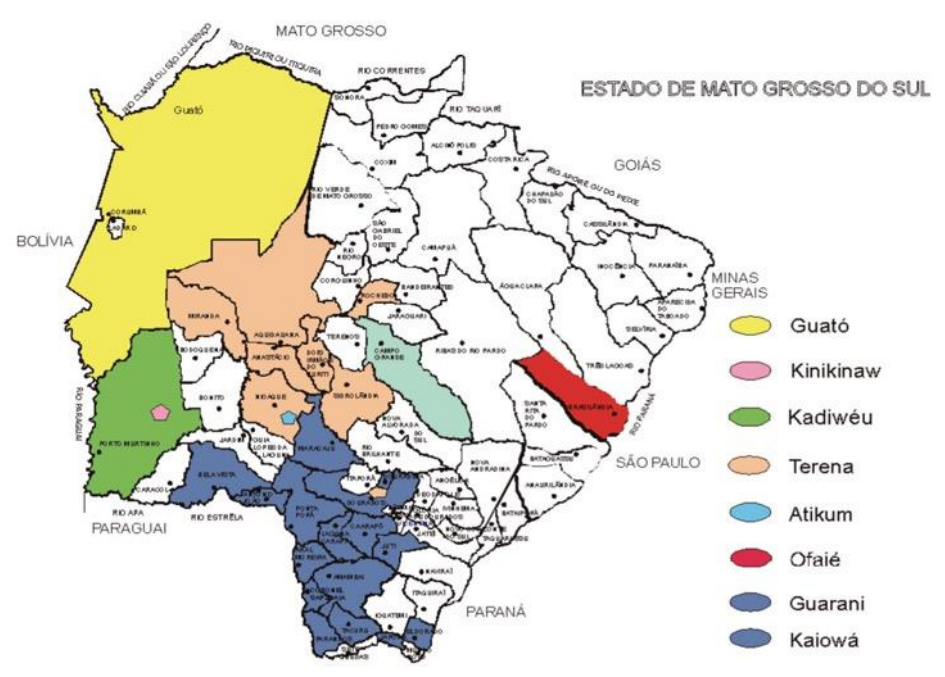

Fonte: FUNASA/DSEI-MS, 2010

Atualmente, apenas quatro indivíduos falam a língua materna, sendo que apenas dois vivem na aldeia. Segundo Oliveira (2006), a vontade de preservar a língua é uma característica marcante entre os Ofaié, o que servirá para nortear nossa discussão sobre o contato linguístico no próximo item.

\section{Contato de línguas: algumas reflexões}

Sabe-se muito pouco sobre o contato entre as línguas faladas no mundo dentre as mais de sete mil línguas existentes atualmente. A necessidade de comunicação é o critério indispensável para o contato linguístico. Para Trask (2004), poucas línguas estão isoladas o bastante para evitar algum tipo de proximidade, logo, as línguas mostram algum tipo de contato antigo ou moderno com outras línguas.

Thurston (1987) corrobora com isso ao defender que toda língua deve ter sofrido algum tipo de influência de povos vizinhos em algum ponto e momento histórico. Assim, 


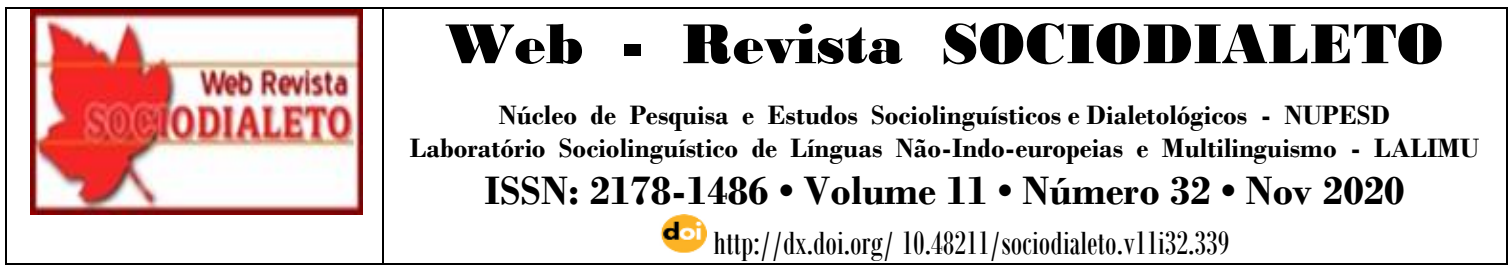

todas as línguas são mistas, no sentido que reproduziram formas lexicais e outros recursos linguísticos de seus vizinhos.

Weinreich foi quem cunhou o termo "língua de contato". Para Couto (2007), o melhor termo é "Contato de Línguas". Segundo o autor, os povos-línguas são os que entram em contato. Assim, ele afirma,

[...] o que se chama de contato de línguas não é nada mais nada menos do que um tipo especial de interação ou comunicação de dois membros de EFLs diferentes, mesmo que, no início, se trate de apenas de tentativas de comunicação, uma vez que um deles fala uma língua (L1) e o outro fala outra língua (L2), línguas que podem ser tipologicamente muito diferentes uma da outra. (COUTO, 2007, p. 283)

O termo utilizado por Couto (2007) "Contato de Línguas" tem a ver com fato de ele considerar um processo. Para o autor, "não pode ser encarado como se tratasse apenas de línguas em contato. Do contrário, estaríamos pensando em duas línguas que estão em contato, como nas situações de fronteiras [...]” (p. 283). Assim, este trabalho, com base em seu caráter político-linguístico em que se encontra a língua Ofaié, optou por manter os pressupostos do autor, no que tange à denominação "Línguas de Contato". Porém, não é possível se distanciar das colocações de Weinreich (1970) sobre o contato linguístico, ou seja, quando a mesma pessoa utiliza alternadamente uma ou mais língua devido o contato. Os estudos de "Línguas de Contato" devem ser investigados dentro dos seguintes aspectos: fonético, gramatical e lexical, com o objetivo de verificar a interferência devido o contato entre as línguas envolvidas.

Segundo Weinreich (1970), a extensão, a direção e a natureza da interferência de uma língua sobre outra podem ser elucidadas de forma mais ampla a partir do comportamento de fala de indivíduos bilíngues, condicionados por relações sociais na comunidade em que estão inseridos.

Couto (2017) amplia algumas questões relacionadas à interpretação de Weinreich (1970 [1953]) quando contra argumenta que o contato de línguas não ocorre somente no indivíduo, ou seja, na mente do falante. Ele coloca que "o que entra em contato 


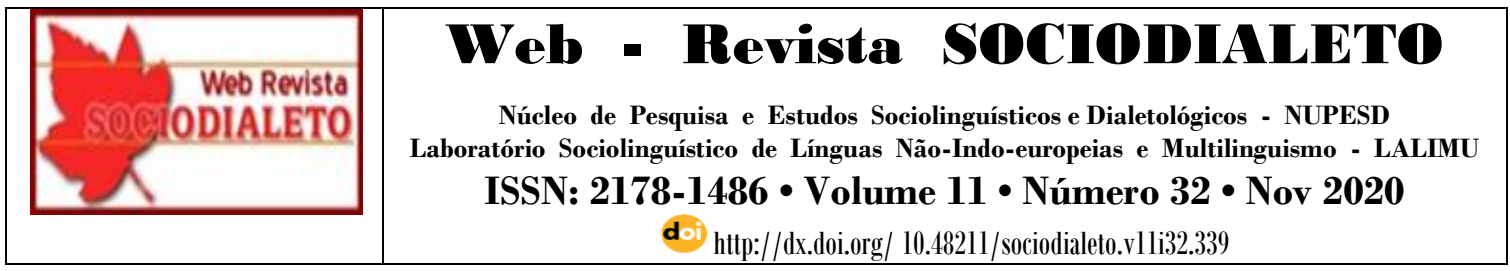

diretamente não são línguas (L), mas povos (P), ou melhor, representantes deles, devido ao fato de L não ter vida fora de P, de que é uma espécie parasitária.” (p. 284). Com isso, suas colocações sobre contato de língua são ampliadas para o que ele chama de Ecologia do Contato de Línguas (doravante ECL).

Sobre o contato linguístico o conceito de "mescla" (TARALLO E ALKIMIN, 1987) é fundamental para descrever a relação entre as línguas e seus resultados. O conceito serve para descrever algo "impuro", "definhamento", "deterioração". Tal conceito pejorativo levou o senso comum a estabelecer a noção de formas impuras, o que acabou fomentando uma ainda presente discriminação linguística.

Neste ponto, este trabalho de abordagem da criação lexical e empréstimos linguísticos na língua Ofaié, refere-se ao que realmente são frutos de uma ECL, visto que todo acréscimo lexical, só se dá por meio da aceitação da população e não de um único indivíduo, conforme veremos adiante.

\section{Observações sobre a criação lexical}

\subsection{A criação lexical}

Toda sociedade humana está em constante mudança, sejam mudanças aceleradas ou lentas. Tais transformações perpassam todos os aspectos da vida humana, incluindo a cultura, e como a língua está ligada intimamente à cultura e às mudanças culturais, elas se manifestam no cotidiano.

O desenvolvimento da Lexicologia em três áreas - (i) a semântica; (ii) o domínio de "palavras e coisas" e (iii) a geografia linguística - ligaram o léxico à cultura. Tal relação é estabelecida por intermédio da relação entre as "novidades" ocorridas no léxico e as motivações sociais que sustentam tais ampliações e mudanças lexicais. E é por meio do léxico, um dos elementos linguísticos que desloca de uma língua para a outra, desaparece e reaparece, ganha ou perde sentidos ou adapta-se à língua em que é 


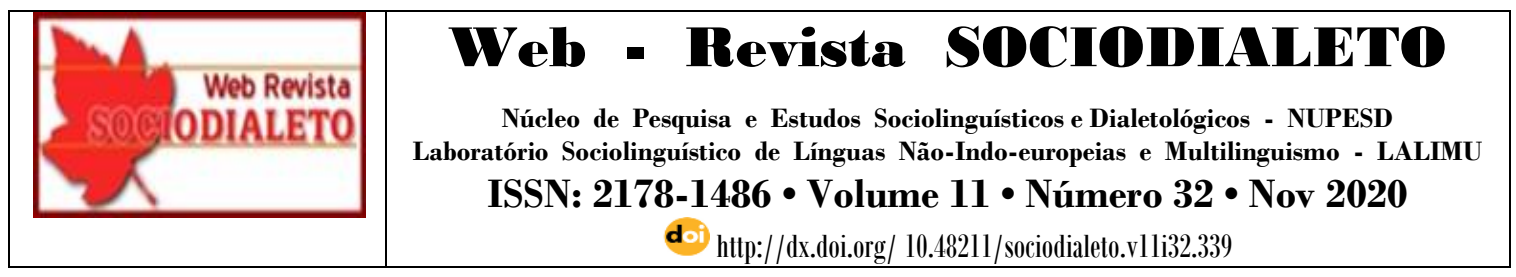

emprestada. Assim, a língua está em constante variação (e mudança) incentivada pelas variáveis sociais, econômicas e culturais.

O léxico de uma língua natural é patrimônio vocabular de um grupo ao longo de sua história, estabelecendo uma herança de signos (lexicais) herdados e de uma série de padrões categoriais para criar novas palavras.

O processo de criação e ampliação lexical não deveria causar estranhamento, já que ocorre em todas as línguas. É por meio do contato com coisas ou realidades inéditas que o falante lança mão do conhecimento linguístico de sua língua para designar aquilo que lhe é novidade. No contato entre os povos, os empréstimos ocorrem no contato de línguas. Na Língua Portuguesa, por exemplo, pode-se citar inúmeros casos de empréstimos, desde futebol < football ou abajour < abat-jour, ou os mais modernos como escaner < scan, clicar < to click, tuitar < twitter, entre outros. Ferraz (2006) aponta que "[...] o surgimento de novas unidades na língua, os neologismos lexicais, são ocorrências naturais, previstas nos padrões de estruturação lexical das línguas vivas." (FERRAZ, 2006, p. 253)

As inovações são governadas por três mecanismos linguísticos: a neologia formal (a unidade léxica criada a partir dos padrões de formação e estruturação lexicais disponíveis na língua), a neologia semântica (a forma lexical já dicionarizada que se apresenta com uma significação diferente da atestada) e a neologia de empréstimos (um estrangeirismo lexical que é adotado pelos falantes) (CORREIA, 2012).

Assim, o léxico é formado por um conjunto de vocábulos que concebem a herança sociocultural de um grupo. O léxico tem relação com a história cultural de um grupo social. A associação entre língua, história e sociedade vem sendo enfatizada desde Saussure, passando por Meillet, que entendia o caráter social da língua e de suas mudanças, e Matoré, que reconhecia as relações entre sociedade e léxico.

Renault-Lescure (2000) ao descrever os processos de formação de palavras em Kali'na, da Guiana Francesa, apresenta a questão de percepção linguística apresentada 


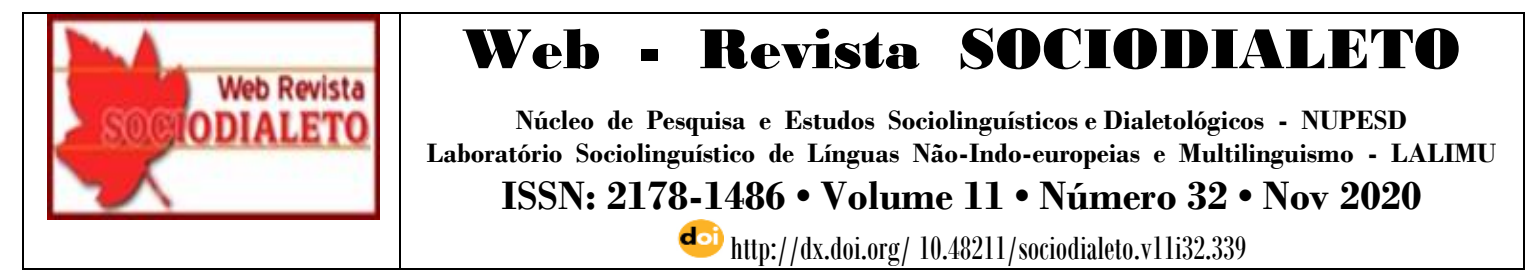

por Pottier (1987), denominada por ele de "percurso de denominação", apresentando-o da seguinte forma:

$$
\begin{array}{lll}
\text { Referente } & \rightarrow \text { conceituação } & \rightarrow \text { escolha de um signo linguístico } \\
\text { (real ou imaginário) } & \rightarrow \text { (representação) } & \rightarrow \text { (adequação relativa) }
\end{array}
$$

Segundo Pottier (1987, p. 45 apud RENAULD-LESCURE, 2000, p. 87), “para todos os referentes habituais de uma cultura, a língua dispõe de uma denominação que vem imediatamente à mente da comunidade", ainda complementa "que será uma lexia mais adequada, sem busca conotativa para designar o referente". Isso decorre do fato de que os povos estão em contínuo contato linguístico e cultural, favorecendo inúmeras interferências e trocas tanto culturais quando linguísticas. Assim, conforme dito acima, toda língua se depara, em determinado momento, com o novo e consequentemente com uma rica criação de palavras. Como foi, e continua sendo, com os povos indígenas.

Adotando essa acepção de léxico, este trabalho busca mostrar como alguns aspectos culturais refletem-se no acervo léxico dos Ofaié, ou seja, mudanças sociais produzem mudanças nas práticas linguísticas.

\subsection{A criação lexical em Ofaié - fruto do contato de línguas}

A criação lexical foi inevitável nas línguas indígenas brasileiras, não só as indígenas, mas também as não indígenas (asiáticas, africanas, línguas de sinais, entre outras). Renault-Lescure (2000, p. 85) aponta que alguns grupos indígenas se colocaram com resistência ao novo, dificultando a inserção de empréstimos em sua língua, como é o caso dos Matis na época de contato; outros como os Malinche (México) incorporaram usos do espanhol na língua (code-switch) bastante intenso. Diante disso, observa-se o comportamento dos neologismos na língua Ofaié, uma comunidade indígena, como já exposto anteriormente, que está em um processo de perda linguística bastante avançado 


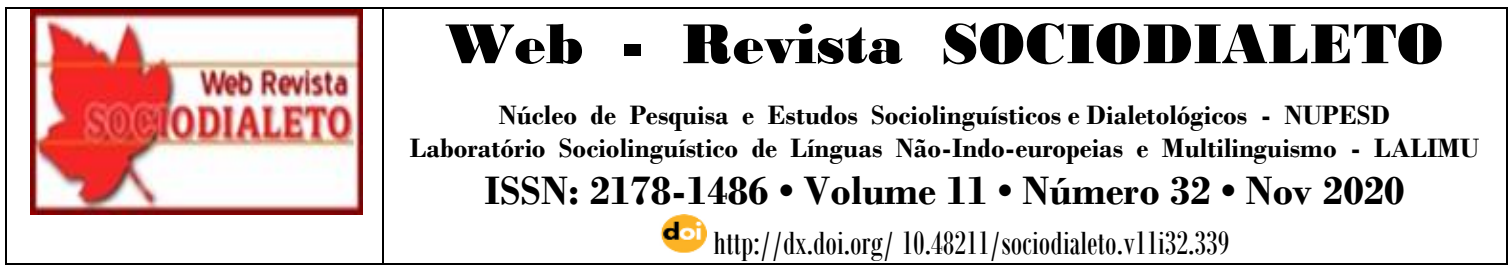

devido sua história mais recente de deslocamentos e, sua total inserção na cultura envolvente, fez com que a incorporação de itens novos e de empréstimos fosse intensa.

Os Ofaié, ao se depararem com as mudanças sociais e, como é comum nestes casos, incorporaram um processo de criação lexical, , utilizando dos recursos linguísticos para denominar o "desconhecido" ou a "novidade". Assim foi o caso de palavras como fwin noegi "balde", esse novo item vem da composição de fwin "água" mais noegi "lugar de". Pode-se encontrar na língua Ofaié do processo de referente até o de escolha linguística itens de neologismo semântico, como é o caso apresentado por Alencar (2014), iäkä "copo ou prato", que tem como referente a ideia do "coco", que por analogia utilizaram para "copo" e por extensão, para "prato", mas acrescentado de fwe "plano/chato". Além disso, encontram-se os empréstimos, como é o caso de kaxoro "cachorro".

\subsection{Os neologismos da língua Ofaié em Curt Nimuendaju (1932[1909])}

Curt Nimuendaju, de 1932, traz uma lista de vocábulos da língua ofaié coletada em 1909, divulgando que dentre os itens lexicais, já haviam sido encontrados alguns neologismos. e . Os itens lexicais neológicos apresentados por Nimuendaju são diferentes dos coletados recentemente, embora haja alguns itens semelhantes, com algumas poucas diferenças fonéticas. Pode-se levantar duas hipóteses: (i) houve uma mudança de pronúncia ou (ii) os transcritos por Nimuendaju foram representados fonéticaortograficamente.

Em 1909, os Ofaié tinham pouco contato com os não indígenas, o que sugere que no processo de criação lexical, o processamento entre Referente, posteriormente, Conceituação, por fim, Escolha de um signo linguístico apresentado por Pottier (1987) levaram os Ofaié a um processo neológico, diferente que ocorrera após um contato mais intenso linguisticamente. 
Núcleo de Pesquisa e Estudos Sociolinguísticos e Dialetológicos - NUPESD Laboratório Sociolinguístico de Línguas Não-Indo-europeias e Multilinguismo - LALIMU ISSN: 2178-1486 • Volume $11 ・$ Número 32 ・ Nov 2020 doi http://dx.doi.org/ 10.40211/sociodialeto.vlli32.339

No levantamento lexical de Loukotka (1931) observam-se alguns empréstimos devido o contato linguístico dos Ofaié com outro grupo indígena. Por exemplo, a palavra "galinha” em Ofaié é inambú, enquanto na família Tupi tem-se nambá. O mesmo ocorre com a palavra "cacique” töšóu em Ofaié, enquanto em Tupi é tušáu. Nesses dois casos, observamos que "O que entra em contato diretamente entre si não são línguas (L), mas os povos ou populações (P) que as falam, ou mais frequentemente, membros representantes desses povos" (COUTO, 2017, p. 31)

A palavra "cacique" töšóu reflete essa hipótese de Couto (2017). Apenas devido ao contato de povo $(\mathrm{P})$ que um item lexical com um significado de poder consegue entrar na categoria de palavras novas absorvidas. A mudança linguística para $x e f i$, na atualidade, parece ter relação com alguns fatores, como o intenso contato com a língua portuguesa; a perda da língua pelos Ofaié mais novos; a "imposição" de órgãos públicosna nomeação do líder de "chefe" quando não referem a "cacique".

A seguir apresentamos um quadro com algumas criações lexicais a partir de Nimuendaju em comparação com os da atualidade.

Quadro 1: Comparação de alguns itens lexicais do Ofaié de 1932 e atual

\begin{tabular}{c|c|c}
\hline Português & Loukotka (1931) / Nimuendaju (1932 [1909]) & $\begin{array}{c}\text { Marilda-Xartã } \\
\text { (2015) }\end{array}$ \\
\hline pano & gara & kraha'ä \\
\hline cama & aša & Hokote \\
\hline brinco & hegerĩdn & kägänĩ \\
\hline canoa & họu-mé & Häwe \\
\hline boneca & e-šaḍ & ---- \\
\hline galinha & inambú (tupi: nambá) & kri'i \\
\hline quatro & witẹyídnitẹ & kuato'é \\
\hline cinco & tẽhahága & sĩko'é \\
\hline seis & nyukári hẹgẹtá & Sejé \\
\hline chefe & töšóu (tupi: tušáu) & Xefi \\
\hline
\end{tabular}




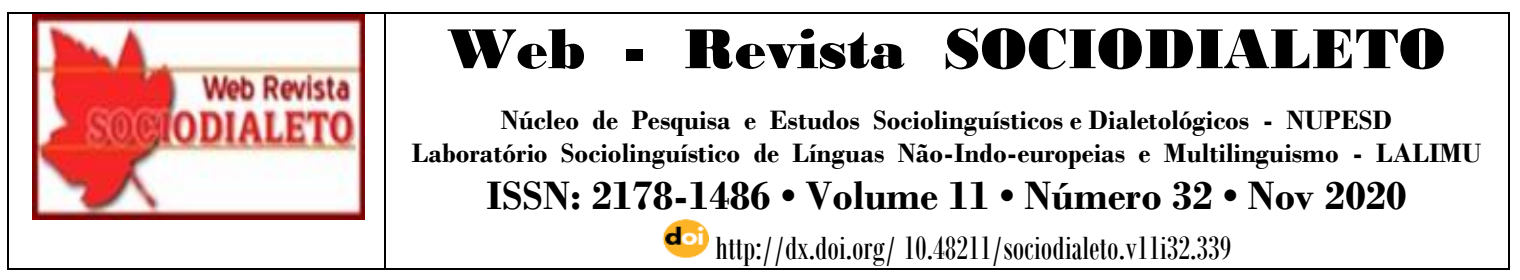

Note-se que a não presença de empréstimos da língua portuguesa ${ }^{5}$ na lista apresentada por Nimuendaju (1932 [1909]). Porém, com apenas 50 anos, no trabalho de Gudschinsky (1971 [1959]) é possível encontrar alguns itens lexicais por empréstimo, por exemplo, kaxoro [kafo'ru] "cachorro", conforme citado acima.

\subsection{Palavras novas em novos tempos}

Conforme já mencionado, os neologismos podem ser divididos em três partes: formal, semântico e por empréstimos. Gonçalves (2016) explica que palavras novas surgem quando "novos fenômenos ocorrem ou quando surge um conceito diferente ou, ainda, um objeto é inventado" (p. 12). Quando tais novidades surgem de fora da sociedade/língua ocorre a apropriação da palavra original, adaptando-se a estrutura da língua receptora. Na Língua Portuguesa, por exemplo, o equipamento de informática "escâner" foi adaptado não somente foneticamente, mas também morfologicamente, visto que a palavra original é "scan", ao importá-lo inseriu-se a vogal [e] no onset da palavra e o morfema "-er" na coda, que tanto o torna um nome quanto um verbo e que acaba por ser conjugado, como no exemplo: "O rapaz escaneará seu documento."

Outra forma que as línguas utilizam na criação de novas palavras é quando usam recursos linguísticos pertencentes à sua língua. Neste momento as flexões, derivações, afixações, entre outros, entram e servem como ferramenta para formação de palavras, como é o caso de alguns afixos. Gonçalvez (2016) apresenta os seguintes exemplos: “destucan-iza-ção”, “des-capet-izar”, "re-dolar-izar”. O processo é semelhante nas línguas indígenas, só que ocorre em muitos casos nestas línguas é o processo de composição para formar palavras novas.

\footnotetext{
${ }^{5}$ É possível que a palavra para "vaca" encontrada em Nimuendaju tenha sofrido mudança, mas que em um primeiro momento fora um empréstimo, pois ele apresenta o seguinte: woke, já em Gudschinsky, em seu artigo Fragmentos de Ofaié, ela apresenta a palavra wa'keq, que se aproxima com a pronúncia de "vaca", atualmente tem-se apenas o item oke.
} 


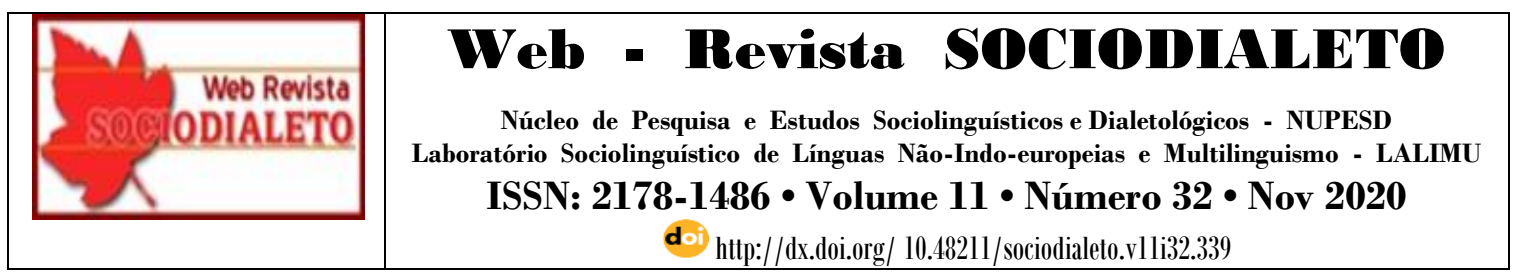

Em Ofaié, segundo Alencar (2014), o neologismo formal apresenta mais dados, com setenta e sete fichas, ficando em segundo os empréstimos, com quinze fichas, e por fim, o neologismo semântico, com nove fichas. Isso corrobora com nossos dados coletados anteriormente aos de Alencar.

\subsubsection{Neologismo de forma}

Os neologismos de forma são aqueles que criados a partir de processos de formação de palavras já conhecidos na língua, tais como: sufixação, prefixação, composição, reduplicação. A denominação de referentes novos leva também à criação de novos signos linguísticos a partir de elementos léxicos e gramaticais já existentes na língua e reunidos de acordo com procedimentos gramaticais regulares de derivação e determinação. (RENAULT-LESCURE, 2000).

\section{Composição}

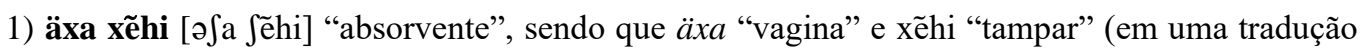
literal seria tampar a vagina).

2) känawha fwi'ä [kənawha фwi'?a] "avião", sendo que känawha "carro (casca de tatu)" e fwi'a "céu" (em uma tradução literal seria a casca da tatu que está no céu (voando))

3) ĩtäfwe kägänĩ [itəфwe kəgənĩ] "brinco", sendo ĩtäfwe "orelha" e kägänĩ "enfeite" (em uma tradução literal enfeite da orelha)

\footnotetext{
Afixação

4) fwuinoege [фwĩnoe'ge] "balde", sendo que fũi +noege "água+ estar dentro"

5) äxäita [əSəjta] "camiseta", sendo que ä-xäi-ta "3p.poss.+vestir+menor"

6) hetängi [hetəngi] "ventilador ou ventania", hetän+gi "ventar+causativo"

7) hetxagi [het [agi] "geladeia", sendo que hetxa +gi "frio/gelado+causativo"

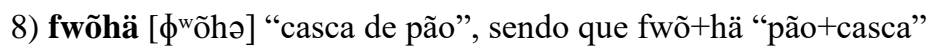




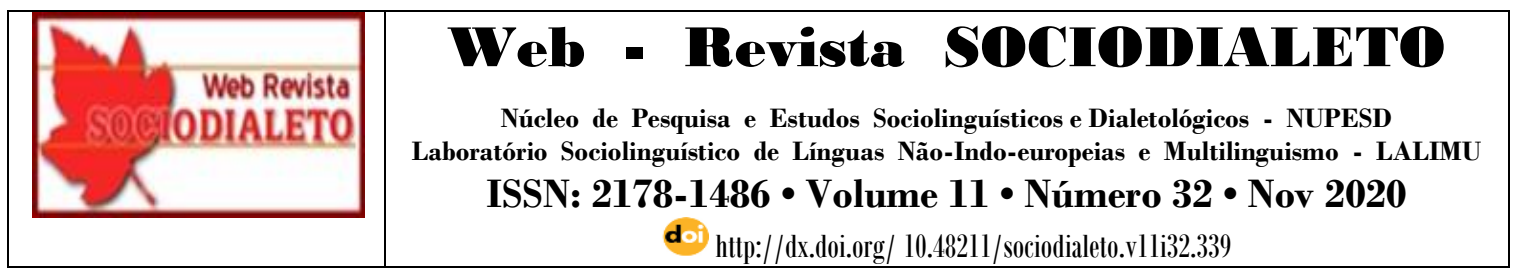

\subsubsection{Neologismo de Sentido}

Os neologismos de sentido são aqueles cujos significantes já existem na língua, mas com sentido diferente do usualmente empregado. Para Correia (2012, p. 62), os neologismos de sentidos são "um dos processos mais produtivos de inovação vocabular consiste na aquisição de novos significados por parte de palavras já existentes.” RenaultLescure (2000) coloca que "os campos semânticos ou léxicos são definidos a partir de microcampos de experiência tirados da realidade do contato vivido pelos locutores" (p. 98). Em Ofaié, encontram-se algumas palavras a partir de uma extensão de sentido, como é o caso da palavra "desodorante", o que levanta a seguinte hitpótese: ao depararem com o objeto novo, o que destacou foi a questão do odor/cheiro; com isso, ao invés de buscarem uma nova forma para designar "desodorante", utilizam a palavra "ängaia" [ãgaja] que significa "cheiro", o que é mais direto entre o novo e a nova designação.

Dessa forma tem-se:
9) känawara [kənawara] "carro”, que vem por comparação de casca de tatu
10) kätek [kətek] "espingarda", que vem por associação a barulho alto.
11) iäkä [ jəkə] "prato/copo", quem vem da palavra coco.
12) fwokta'e $\left[\phi^{\mathrm{w}} \mathrm{okta}, \varepsilon\right]$ "guarda-chuva", que vem da palavra morcego.

\subsubsection{Empréstimo}

Uma das consequências do contato linguístico está no empréstimo que as línguas fazem entre si. Esse processo é analisado por meio da comparação de mudanças que podem ocorrer na língua, como é o caso de aspectos da sonoridade, da alteração morfológica e sintática, entre outros aspectos também como a criação de neologismos. Quando se observa a palavra, verificamos que os empréstimos não necessitam de uma profunda intensidade no contato de línguas para essas mudanças ocorram. Contudo, não se pode deixar de levar em consideração o que "o empréstimo não é nunca uma 


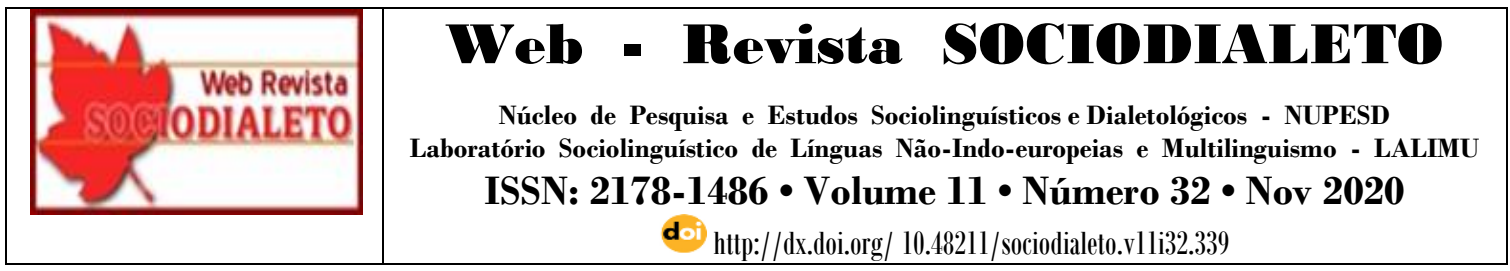

necessidade linguística, visto ser sempre possível ampliar e modificar o uso das unidades lexicais existentes para fazer face às novas necessidades de comunicação" (LANGACKER, 1972, 186).

Como exemplo, vamos apresentar algumas palavras emprestadas do português para a língua Ofaié. No processo de adaptação observamos que tanto a oclusiva [p], quanto a fricativa [f], são pronunciadas pelo fone coarticulado $\left[\phi^{\mathrm{w}}\right]$.A sequência consonantal [tr] é substituída pela sequência [gr], isso ocorre devido ao fato de não se ter [tr] e por ser produtivo [gr]. Na palavra para "cachorro", Alencar (2014, p. 79) coloca que:

\begin{abstract}
A palavra [kafo'ro] vem sendo usada para designar o animal. Porém, durante nossas coletas vimos que outra palavra era anteriormente utilizada: [õt $f i$ 'gat ] composta por [õtti] "onça" + [gatz] "branca" que também significa "cachorro", em ofayé. Em algum momento, o léxico [õtfi'gate] deixou de ser atualizado quando havia a necessidade de mencionar o animal, a partir disso, [kafo'ro] tornou-se mais frequente.
\end{abstract}

Esta colocação de Alencar vem ao encontro da exposição de Nettle e Romanine (2000, p. 550) de que “em seus estágios finais, uma língua que está morrendo deverá ter tomado inúmeras palavras da nova língua, algumas delas para coisas novas, mas outras substituindo palavras nativas."

Os empréstimos em Ofaié são fruto do contato linguístico e da forma que o português ocupa o espaço de fala, mesmo apesar de ser uma língua que está em perigo de extinção, e apesar de não falarem mais entre si na língua materna, estas palavras emprestadas ainda preservam estes as características fonológicas da língua alvo.

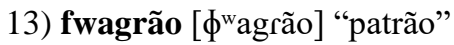
14) kaxoro [kaforo] "cachorro"

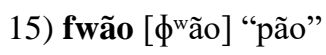
16) kafwé $\left[k a \phi^{w} \varepsilon\right]$ "café"

\title{
4. Considerações finais
}




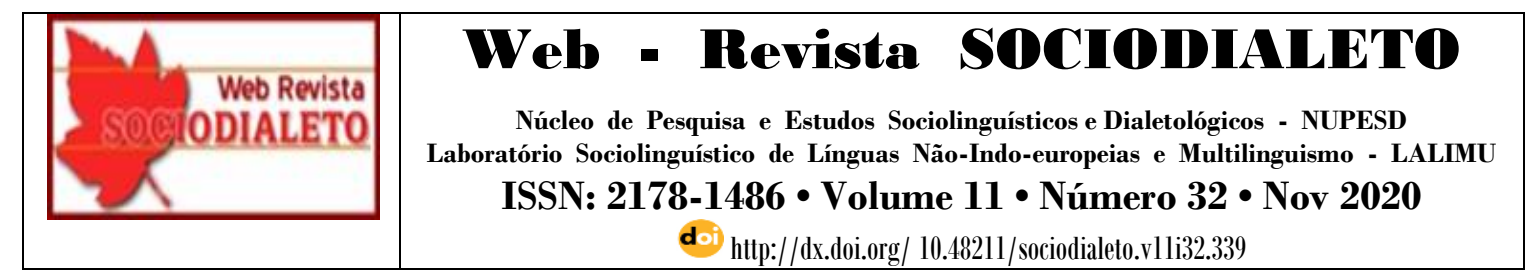

Como ocorrem em outras línguas, os Ofaié lançam mão dos recursos linguísticos para a criação de palavras novas. Na Língua Portuguesa do Brasil, por exemplo, criamse palavras novas de forma bastante "rotineira", ao ponto de nem se perceber e se dar conta da sensação de novidade. Basta observar alguns empréstimos como bullyng, ou nerd, ou ainda, o uso das palavras "mensalão" e "petróleo", que devido ao uso, nem são percebidas como palavras novas.

Entretanto, quando se pensa na questão indígena, principalmente quando se leva em consideração os povos em que o contato é recente, como é o caso dos Matis, ou não tão recentes, como os Ofaié, aqui descritos, as palavras novas são percebidas facilmente pelo povo.

Os neologismos, no caso dos Ofaié, são ainda estáveis entre os poucos falantes, devido a perda rápida de sua língua. Quase não se ouve palavras emprestadas e adaptadas do português, mantêm aquelas que seus parentes elencaram para denominar esse ou aquele objeto.

Devido à perda linguística, os falantes restantes não conseguem resgatar a origem de certas palavras novas. Nesse caso, houve uma grande mudança fonológica da palavra ou realmente se perdeu o sentido original.

O que importa neste momento é que o povo Ofaié está em busca de resgatar sua língua, algo complicado e se não, impossível.Desse modo, o desafio é conhecer e levar até este povo as palavras criadas desde seus bisavós como um compromisso de regate e de preservação linguística para que dentro de suas características atuais possam manter em algum nível tal conhecimento.

Esse trabalho faz parte de um projeto maior, chamado "Manutenção da Língua Ofaye: um estudo lexical", no qual como uma das ações, pretendemos contribuir com a elaboração de um dicionário escolar para a comunidade indígena para queo material venha a ser mais um ponto de apoio para a manutenção e a valorização cultural da língua ofaié e quem sabe, de aspectos da fala. 


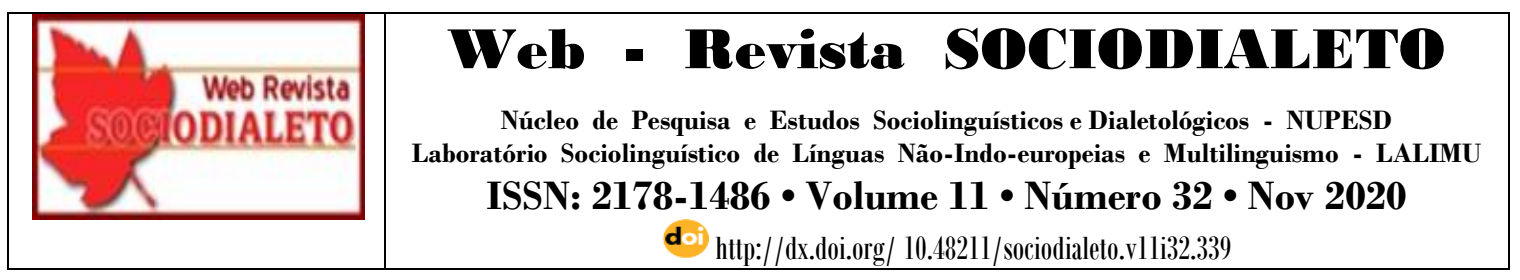

\section{Referências}

ALENCAR, Fabíola Tobias de. Neologismo na Língua Ofaié. 2014. Dissertação (Mestrado em Letras) - Universidade Federal de Mato Grosso do Sul.

CORREIA, Margarita. Neologia em português. São Paulo: Parábola, 2012.

COUTO, Hildo H. do. Contato interlinguístico - da interação à gramática. Brasília: Programa de Pós-graduação em Linguística, Universidade de Brasília, 2017. Disponível em < http://www.ecoling.unb.br/images/e-book-Forma.pdf>. Acesso em 11 out. 2020.

COUTO, Hildo H. do. Linguística, ecologia e ecolinguística: contato de línguas. São Paulo: Contexto, 2009.

DUTRA, Carlos Alberto dos Santos. O território ofaié: pelos caminhos da história. Editora Life. Campo Grande, 2011.

FERREIRA, Rogério V. Palavras Ofaié: um resgate da memória lexical. Campo Grande: UFMS, 2017.

FERRAZ A.P. A inovação lexical e a dimensão social da língua. In: SEABRA, M.C.T. C. De (Org.) O léxico em estudo. Belo Horizonte: FALE/UFMG, 2006, p. 217-234.

FERRAZ A.P. Publicidade: a linguagem da inovação lexical. In: ALVES, Ieda. M. (Org.) Neologia e Neologismos em diferentes perspectivas. São Paulo: Paulistana, 2010. p. 251-275.

FUNASA/DSEI-MS. Relatório Anual de Gestão de 2009. Publicação institucional, 2010.

GONÇALVES, Carlos Alexandre. Atuais tendências em formação de palavras. São Paulo: Contexto, 2016.

LANGACKER, Ronald W. A linguagem e sua estrutura. Trad. Gilda Maria Corrêa de Azevedo. Petrópolis: Vozes, 1972.

LOUKOTKA, Estmír. Les Indiens Kukura du río Verde, Matto Grosso, Brésil. Journal de la Société des Américanistes. Tome 23-1, 1931. pp. 121-125.

NETTLE, D. \& ROMAINE, S. Vanishing Voices. The extincion of the wold's languages. Oxford: Oxford University Press, 2000.

NIMUENDAJU, Curt. Idiomas Indígenas del Brasil. Revista del Instituto de Etnologia de la Universid Nacional de Tucuman 2. 1932 [1909]. p.543-618.

OLIVEIRA, Maria das Dores. Ofayé, a língua do povo do mel: fonologia e gramática. 2006. Tese (Doutorado em Letras e Linguística) - Universidade Federal de Alagoas.

RENAULT-LESCURE, Odile. As palavras e as coisas do contato: os neologismos Kali'na (Guiana Francesa). In: ALBERT, Bruce; Rita Ramos, Alcida (eds.). Pacificando 


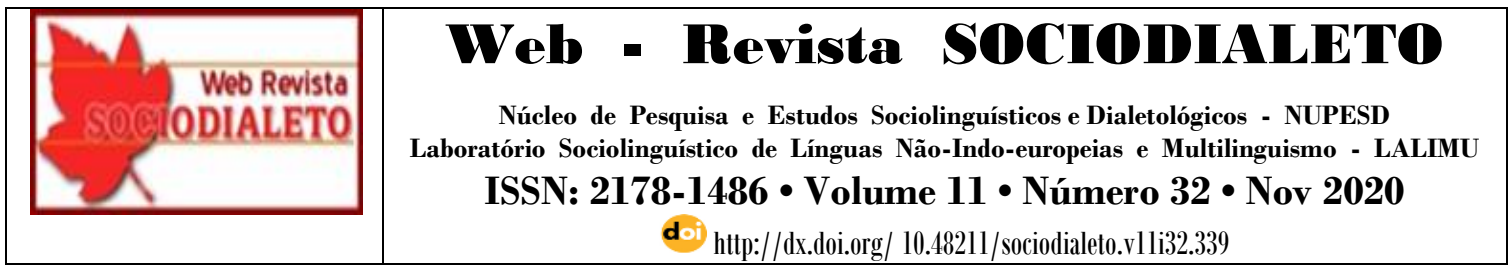

o branco: cosmologias do contato no norte-amazônico. São Paulo: UNESP, 2002. p. $85-112$

RODRIGUES, Aryon D. Línguas brasileiras: para o conhecimento das línguas indígenas. São Paulo: Loyola, 1986.

SILVA, Jennifer Ellen. Aspectos morfossintáticos dos verbos na língua Ofaié. 2012. Dissertação (Mestrado em Letras). Universidade Federal de Mato Grosso do Sul.

SIQUEIRA, Simoni S. A trajetória do povo ofaié: territorialidade e reconhecimento de direitos territoriais. In: XIV Encontro de História da ANPUH/MS - "História: o que é, quanto vale, para que serve?", 2018, Dourados. Anais [...]. Dourados: Mato Grosso do Sul: Universidade Federal da Grande Dourados, 2018. s/p

TARALLO, Fernando \& ALKIMIN, Tânia. Falares Crioulos: Línguas em contato. São Paulo: Ática, 1987.

TRASK, R. L. Dicionário de Linguagem e Linguística. São Paulo: Editora Contexto. 2004.

THURSTON W. F. Processes of change in the languages of northwestern. New Britain. Canberra: Pacific Linguistics, 1987.

WEINREICH, U. Languages in contact: Findings and Problems. 7th. ed. Mouton: Den Haag, 1970. 


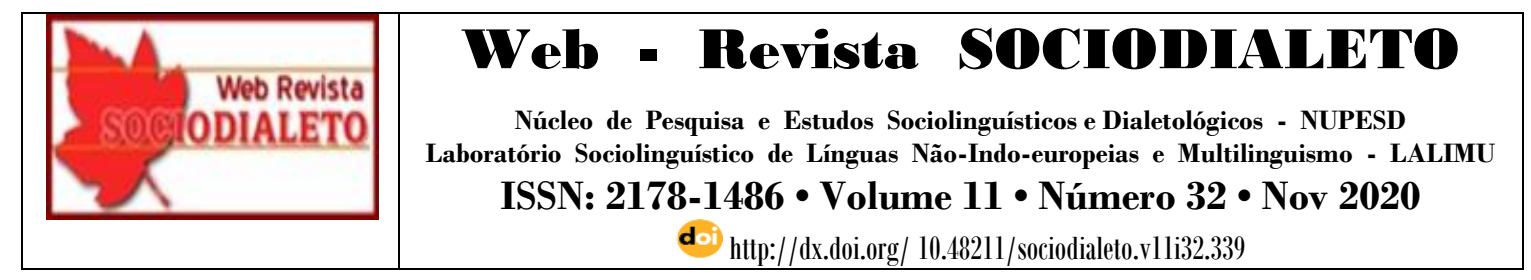

Recebido Para Publicação em 23 de outubro de 2020. Aprovado Para Publicação em 03 de novembro de 2020. 